\title{
Surgical Techniques to Reduce the Diminished Ovarian Reserve Risk of Endometrial Cyst
}

\author{
Muhammad Rusda ${ }^{1 *}$ D , Ichwanul Adenin ${ }^{1}$, M. Oki Prabudi ${ }^{1}$, J. Syaputra ${ }^{1}$, Andrina Yunita Murni Rambe ${ }^{2}$ \\ ${ }^{1}$ Department of Obstetrics and Gynecology, Endocrinology Reproductive Division, School of Medicine, Universitas Sumatera \\ Utara, Medan, Indonesia; ' Department of Otorhinolaryngology, School of Medicine, Universitas Sumatera Utara, Medan, \\ Indonesia
}

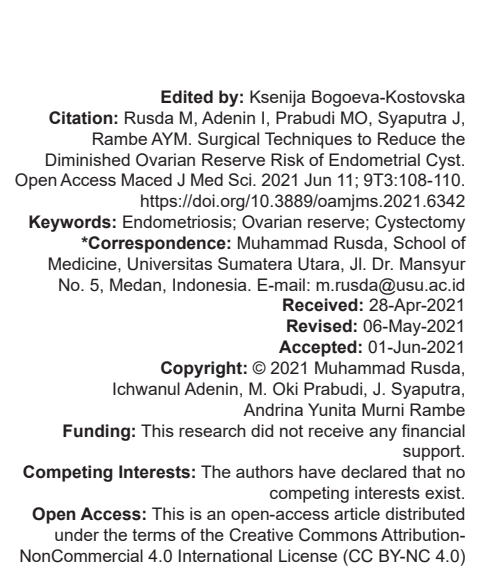

Introduction

Endometriosis is a gynecological condition characterized by the presence of endometrial glands and stromal cells in the extrauterine [1]. The prevalence of endometriosis in the general population of reproductive age women varies between $3 \%$ and $10 \%$. Clinical manifestation of endometriosis includes dysmenorrhea, chronic pelvic pain, dyspareunia, dyschezia, abnormal uterine bleeding, and infertility. Natural conception can only be achieved on $10-11 \%$ infertile endometriosis patients [2], [3].

Surgical treatment is an important therapy in endometriosis management which aims to remove endometriotic tissue and maintain the maximum amount of normal ovarian tissue [3]. Ovarian reserve (OR) was decreased in women with endometriosis compared to healthy women of the same age or women with benign ovarian cysts [4]. The choice of the surgical technique based on the patient's condition will determine the success of ovarian reserve, because surgery can reduce the number of healthy follicles and damage the surrounding healthy tissue. Therefore, surgical techniques have been developed to reduce the risk of ovarian reserve, such as laparoscopy cystectomy or ablation [5], [6].

\section{Case Presentation}

A 32-year-old woman, P0A0, was presented with lower abdominal pain which has been experienced since 1 year ago. The pain was got worse in the last seven months, intermittent and worse during menstruation. History of vaginal bleeding, prolonged menstruation, vaginal bleeding at the irregular interval, bleeding during sexual intercourse, and vaginal discharge was not found. History of consuming traditional herbs was not found. Previously, the patient had consulted to obstetric gynecologist and was diagnosed with right ovarian endometrial cyst.

On physical examination, vital signs and generalized state were within normal limit.

The mobile cystic mass was palpable on abdomen without pain during palpation. The abdomen area was tender to palpate. Vaginal examination showed mobile and smooth surface cystic mass was palpable, upper pole was three fingers below the umbilicus, lower pole was in line with pubic symphysis, and no palpable mass on both adnexal. TVUS was performed and showed enlargement of uterus size $(7.89 \times 4.36 \mathrm{~cm})$, unilocular cyst was found $(9.86 \times 11.65 \mathrm{~cm})$ with homogenous echo pattern which probably came from right adnexa. The 
size of right ovarium was $2.49 \times 2.85 \times 1.58 \mathrm{~cm}$. Septa, papilla, and free fluid were not found (Figure 1).
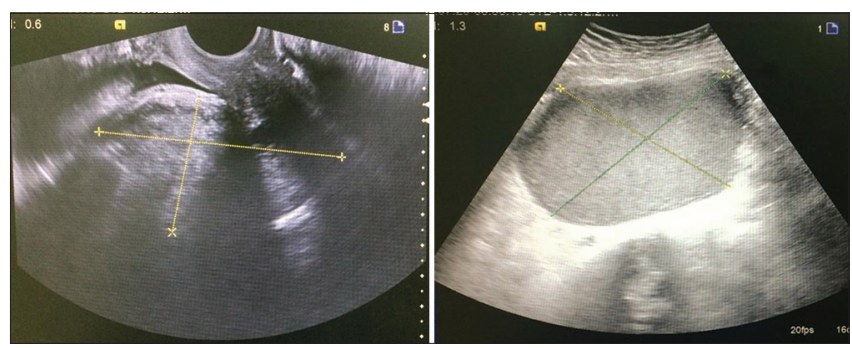

Figure 1: Endometriosis on TVUS

Based on laboratory result, there was marked increase in CA-125 (>600 U/ml). On International Tumor Analysis, tumor was classified as B1 unilocular cyst and the malignancy risk index was 600 . The patient was diagnosed with endometriosis and laparotomy cystectomy was performed.

\section{Discussion}

Endometriosis is a case that often occurs in women of reproductive age [7], which mostly occurred in lower pelvic region, uterosacral ligament, bladder, distal ureter, sigmoid colon, and Douglas pouch. Endometriosis classic manifestation was dysmenorrhea, dyspareunia, dyschezia, infertility, non-cyclic pelvic pain, hematuria, or gastrointestinal bleeding. Endometriosis causes infertility in $20-50 \%$ of cases and pelvic pain in $40-50 \%$ of cases. Acute and chronic gynecological diseases are estrogen-dependent and are the most common causes of pelvic pain [8]. TVUS is the main imaging technique for evaluating endometriosis because of its value of money and availability. TVUS can detect the presence of endometriosis, generally having a unilocular, thickwalled, and homogeneous cyst with low echogenicity (ground glass appearance) [9]. The gold standard examination in diagnosing endometriosis is visual inspection of the pelvis with laparoscopy. Laparoscopy can inspect the ovaries, fallopian tubes, ovarian fossa, sacrouterine ligament, Douglas pouch, uterovesical folds, rectosigmoid, and appendix [9]. Our patient was a reproductive age woman presented with the lower abdominal pain which worse during menstruation. Patient's TVUS result showed enlargement of uterus and right ovarium sizes; and unilocular cyst with homogenous echo pattern. Laparoscopy was not performed in this patient due to SARS Cov-2 Pandemic reason.

Surgery is still an option for endometriosis management because of its efficiency. Laparoscopic cystectomy is the first choice for endometriosis treatment. The presence of large endometriosis often requires laparoscopic cystectomy. Ovarian cystectomy reduces $O R$ as assessed by a decreased in the number of oocytes from the operated ovary; however, it was not associated with the success of pregnancy. Infertile women with unilateral endometriosis who underwent either cystectomy or coagulation fenestration, stated that the number of dominant follicles acquired postoperatively laparoscopy was comparable with women who had unilateral endometriosis. The OR of the operated ovary can be compared to a healthy ovary. In a clinical trial study in 2011 showed that the recurrence of endometriosis was less common in patients undergoing cystectomy than in ablation. Besides that, cystectomy was proven to reduce the pain symptoms and increase conception among subfertile patients [10], [11].

Three independent factors have been identified to influence OR after cystectomy and should be considered before planning surgery. First, patients undergoing cystectomy will have lower serum concentrations of anti-Mullerian hormone (AMH) than women undergoing unilateral endometriosis excision. Second, the size of the endometriosis was shown to be related to the number of healthy ovarian parenchyma that was accidentally wasted during cystectomy. However, in women with recurrent endometriosis who plan to undergo assisted reproductive technology (ART), repeated cystectomy has been shown to be associated with an increased risk of impaired ovarian preservation. Clinical trial studies show that $\mathrm{AMH}$ concentrations are significantly lower in patients who underwent a second cystectomy when compared to patients who underwent only one cystectomy [12].

Another technique for OR in endometriosis was carbon dioxide $\left(\mathrm{CO}_{2}\right)$ ablation. Ablation technique is a surgical procedure for the destruction of endometriosis lesions by coagulation using a thermal energy source. The ablation technique can also be done using a vaporization method with a laser power source [13]. Laser ablation is a great option to reduce the chance of ovarian damage. Ablation technique should be considered for endometriosis larger than $4 \mathrm{~cm}$ [10]. Data showed that the use of ablation $\mathrm{CO}_{2}$ and plasma energy could produce lower thermal injury and increase OR compared to cystectomy [13]. The advantage of using ablation $\mathrm{CO}_{2}$ is a high precision, ability on performing surgery without bleeding, lower thermal energy which induced faster recovery, reduce the formation of adhesion, and better pain control [14].

The three-stage approach was used as the management of endometriosis $\geq 3 \mathrm{~cm}$ in size, consisting of laparoscopic drainage of the cysts with biopsy to confirm the diagnosis of endometriosis, therapy with Gonadotrophin Releasing Hormone $(\mathrm{GnRH})$ agonists for 12 weeks with the aim of reducing the cyst diameter and mitotic activity; and laparoscopic ablation of the cyst walls using laser $\mathrm{CO}_{2}$ in the second laparoscopy. Studies showed that healthy ovarian tissue will not be wasted and excessive thermal damage can be avoided using $\mathrm{CO}_{2}$ laser vaporization in the three-stage approach group. The number of antral follicles in patients undergoing the three-stage approach was significantly higher than in patients undergoing cystectomy, which indicates that the three-stage approach is more effective in maintaining ovarian preservation [15]. 
Surgery technique can decrease OR by three main mechanisms: Excessive stripping of the ovarian cortex, use of bipolar coagulation to stop bleeding, and the presence of surgical inflammation. Cyst stripping caused the damage of normal ovarian cortex, which may decrease OR because the follicle is in the cortex. The stripping method with thermocoagulation tends to cause greater follicle damage. The number and volume of antral follicles in patients undergoing this surgical method are lower than in other surgical methods [16]. AMH levels were lower in patients undergoing ovarian stripping, so AMH can be the most reliable tool for assessing OR [17].

One reason of OR diminished after stripping is caused by the damage of primordial follicles due to the destruction of blood vessels and blood supply to the ovaries during hemostatic procedures. Bipolar suture and electrosurgery are the most commonly used methods of hemostasis during ovarian cystectomy. Bipolar coagulation is the most common method of hemostasis because it is very easy and efficient. However, the best method for obtaining good hemostasis is to optimize the dissection by identifying the appropriate area of division during surgery and performing a dissection in that area. Expert hand suture provides excellent hemostasis with minimal damage to ovarian tissue. A good suture method is to approximate and not to strangulate the ovarian tissue which can lead to tissue damage and a very tight knot will disrupt the ovarian blood vessels [18], [19].

\section{Conclusion}

The patient was diagnosed with endometrial cyst and laparotomy cystectomy was performed as treatment. Ovarian cystectomy in infertile women was shown to have comparable OR, reduced pain symptoms, and increased conception among infertile patients.

\section{References}

1. Bulun SE, Yilmaz BD, Sison C, Miyazaki K, Bernardi L, Liu S, et al. Endometriosis. Endocr Rev. 2019;40(4):1048-79. PMid:30994890

2. Hidayat A, Hendry D. Characteristics of Patients With Endometriosis and Adenomyosis in Dr. M. Djamil Padang During January 2017-October 2018. Andalas Obstet Gynecol J. 2019;3(1):1-14. https://doi.org/10.25077/aogj.3.1.29-41.2019

3. Wu IB, Tendean HM, Mewengkang ME. Tendean HM, Mewengkang ME. Description of The Characteristics of Patients with Endometriosis in RSUP Prof. Dr. R.D. Kandou Manado. J E-Clin. 2017;5(2):1-7. https://doi.org/10.35790/ecl.5.2.2017.18568

4. Working group of ESGE, ESHRE, and WES, Saridogan E, Becker CM, Feki A, Grimbizis GF, Hummelshoj L, et al. Recommendations for the surgical treatment of endometriosispart 1: Ovarian endometrioma. Gynecol Surg. 2017;14(1):27. https://doi.org/10.1186/s10397-017-1029-x

PMid:29285022

5. Zanelitti A, DeCherney AH. Surgery and endometriosis. Clin Obstet Gynecol. 2017;60(3):477-84.

PMid:28742580

6. Berek JS, Novak NF, Adams SR, Anderson JR. Berek \& Novak's Gynecology. United States: Lippincott Williams; 2007.

7. Rusda M, Rahman $\mathrm{DH}$. The influence of health promotion on female students' behaviour in SMA An-Nizam Medan about endometriosis. Open Access Maced J Med Sci. 2019;7(20):3366-9. https://doi.org/10.3889/oamjms.2019.424 PMid:32002052

8. Kukstas C. Endometriosis. InnovAiT. 2017;10(9):533-9.

9. Stekly WW, Kew CC, Chern BS. Endometriosis: A review of the diagnosis and pain management. Gynecol Minim Invasive Ther. 2015;4:106-9.

10. Carvalho L, Nataraj N, Rao J, Khetarpal S, Abrao MS Agarwal A. Seven ways to preserve female fertility in patients with endometriosis. Exp Rev Obstet Gynecol. 2012;7(3):228-31. https://doi.org/10.1586/eog.12.19

11. Carrillo L, Seidman DS, Cittadini E, Meirow D. The role of fertility preservation in patients with endometriosis. J Assist Reprod Genet. 2016;33(3):317-23. https://doi.org/10.1007/s10815-016-0646-z PMid:26768141

12. Cranney R, Condous G, Reid S. An update on the diagnosis, surgical management, and fertility outcomes for women with endometrioma. Acta Obstet Gynecol Scand. 2017;96(6):633-43. https://doi.org/10.1111/aogs.13114

PMid:28186620

13. Hendarto HH. Endometriosis: DariAspek Teori Sampai Penanganan Klinis. Vol. 1. Surabaya: Airlangga University Press; 2015. p. 67-76.

14. Paulson JD, Habli M, Alizade A, Borromeo R. The treatment of mild endometriosis with laser laparoscopy: A two-step treatment analysis of patients whose primary therapy was successful. JSLS. 2006;10(1):30-6.

PMid: 16709353

15. Tsolakidis D, Pados $G$, Vavilis D, Athanatos D, Tsalikis T, Giannakou $\mathrm{A}$, et al. The impact on ovarian reserve after laparoscopic ovarian cystectomy versus three-stage management in patients with endometriomas: A prospective randomized study. Fertil Steril. 2010;94(6):71-7. https://doi.org/10.1016/j.fertnstert.2009.01.138

16. Biacchiardi CP, Piane LD, Camanni M, Deltetto F, Delpiano EM, Marchino GL, et al. Laparoscopic stripping of endometriomas negatively affects ovarian follicular reserve even if performed by experienced surgeons. Reprod Biomed Online. 2011;23(6):740-6. https://doi.org/10.1016/j.rbmo.2011.07.014 PMid:22019621

17. Küpker W, Felberbaum RE, Krapp M, Schill T, Malik E, Diedrich K. Use of $\mathrm{GnRH}$ antagonists in the treatment of endometriosis. Reprod Biomed Online. 2002;5(1):12-6. https:// doi.org/10.1016/s1472-6483(10)61590-8

PMid: 12470539

18. Donnez J, Lousse JC, Jadoul P, Donnez O, Squifflet J. Laparoscopic management of endometriomas using a combined technique of excisional (cystectomy) and ablative surgery. Fertil Steril. 2010;94(1):28-32. https://doi.org/10.1016/j.fertnstert.2009.02.065 PMid: 19361793

19. Ozaki R, Kumakiri J, Tinelli A, Grimbizis GF, Kitade M, Takeda S. Evaluation of factors predicting diminished ovarian reserve before and after laparoscopic cystectomy for ovarian endometriomas: A prospective cohort study. J Ovarian Res. 2016;9(1):37. https://doi.org/10.1186/s13048-016-0241-z

PMid:27329142 